\title{
Revival of Tradition in a Taiwanese Aborigines' Community by Means of a Community Development Process-from a Perspective of Agent/Agency
}

\author{
Takako Sasaki
}

\begin{abstract}
This paper took the application of community development (CD) in a Taiwanese aborigines' community and focusing on actors' agent/agency worked inside of the community, (1) clarified how community leaders revived and transformed tradition, (2) considered the viability of their CD practice. The agent/agency of transformative capacity is applicable to $\mathrm{CD}$ of a process of community transformation. Previous studies discussed the concept focusing on a feature of intervention between outsider and the community. A significance of the paper is focusing on inside because it is several residents who start CD although it is said that CD is advanced the community's participation. Involving other residents is a basic step of a CD process and clarifying the step in detail help to measure a community's capacity when not only researchers consider the continuity of $\mathrm{CD}$ in the community, but also outsiders consider how they can cooperate with them about CD. The investigation revealed that a minority leaders' agency appeared in that they selectively revived traditions to form a majority of residents' common feelings. Shifting a perspective of intervention from outside to inside of the community and introducing the concept to Taiwanese aborigines' CD study would be able to develop discussions of decolonization.
\end{abstract}

Index Terms - Taiwanese aborigines, agency, customary law, community development.

\section{INTRODUCTION}

Taiwanese aborigines who, according to previous researches, lived in Taiwan islands before Chinese immigration started in the 17th century, lost their original culture and identity due to the following two events. One is the policies in the Empire of Japan (1895-1945) and Taiwan's government (1945-until the present). The other is conversion to Christianity, which rapidly advanced in 1950s, because Christianity did not accept the aborigines' ancestor worship. In 1980s and later, they started to restore their culture with pride and took ethnic identity back as the social movement and democratic reforms in Taiwan supported Taiwanese aboriginal rights movement. Recently, it has been common that they engage in community development (CD) activities to revive the tradition and to improve their quality of life since Taiwan's government introduced participatory CD by implementing Comprehensive CD policy in 1994.

However, it is not easy for them to achieve expected results due to some reasons. For example, as often happens in such cases, they hastily constructed some traditions, such as

Manuscript received February 20, 2014; revised April 22, 2014

Takako Sasaki is with the Kyoto University, Japan (e-mail: sasaki.takako.68e@st.kyoto-u.ac.jp). arts and music, as tourist attractions and so lost their legitimacy [1]. Sometimes tradition causes a conflict with Christianity even now [2]. Furthermore, Taiwanese aborigines nowadays face the decline of their communities caused by aging and the population flow to cities.

Focusing on residents' action to deal with this modern issue of the decline of the community, this paper aims to discuss residents' independence in a process of CD using a concept of agent/agency, and takes the CD practice in Smangus, a Taiwanese aborigine's community, as an example.

\section{Previous Studies And the Meaning OF AGENT/AGENCY IN THIS PAPER}

\section{A. Agent/Agency and $C D$}

The concept of agent/agency was advocated in post-structuralism instead of subject/subjectivity. Giddens defined the agent as "a power as transformative capacity" generated by actors in their relationship with authority [3]. He also stated that it alters the limitation of the institution of the life by intervention [4]. Researchers developed discussion after Giddens. Tanaka suggested that this "intervention" connotes resistance and communication [5] and defined the agency as the networks of relation generated by these features of the agent [ibid, 5]. Eto stated that the agency acted in a process of capacity building to empower actors' efforts [6].

These discussions are applicable to CD study because CD is also a process of residents' practices to solve the community's issue [7], and the process leads to the transformation of the society. After almost three decades of the definition it is effective even now. Using the definition, Hirota integrated some theories into one CD process in 2010 [8]; Residents face an issue of the community and start actions, then, they solve the issue and continuously repeat the process to improve the community. $\mathrm{CD}$ is advanced by cooperation among stakeholders: administrative bodies offering policy, experts offering technology and residents offering transformative capacity.

Previous CD studies clarified that a key to achieving expected results is that residents share common feelings, for instance, a sense of issue and a common goal, in the community. Meanwhile, studies have found residents' independence in voluntary and self-determination such as, making a CD plan and starting action [9], finding a local resource to improve the community's condition [10], and transforming local knowledge of the community to fit their 
life style [11].

On the other hand, few CD studies focused on who residents were. Generally, a group, such as a community organization or community leaders represented residents. This has been an issue because a group was too big unit to explain some steps which how residents make a common feelings and act on their own initiative in a CD process. However, it is important to clarify processes of steps because these steps foster residents' basic ability to show independence in CD.

\section{B. Previous Studies about Taiwanese Aborigines}

Studies around Taiwanese aborigines' CD which centered on reviving tradition has been accumulated other than previous studies in the preceding section. Taking studies about Smangus' case, Tsai stated a factor which led their CD activities to success was that residents kept their common law and applied it to CD [12]. Napay discussed an education programs about the tradition relating to $C D$ practice [13]. However, Smangus life already changed when they started $\mathrm{CD}$ and revived tradition was not same as the original, as Icheh introduced the result of CD as a new tradition [14]. There is no study which traced a reviving process of tradition focusing on actors involved in it, although it is important perspective to consider a history to restore their identity and to transform their community.

\section{The Meaning of Agent/Agency in the Paper}

It is effective to use the concept of agent/agency here because it specifies actors and explains the transformation of the community through describing interaction among actors. Residents who started CD action are just a part of whole residents even if they are community leaders, and they should need intervention with resistance and communication to other residents to make a common feeling to transform the community. In addition, shifting a perspective of intervention from outside to inside of the community would be able to develop discussions of decolonization, because they tend to discuss based on a confrontation between outsiders such as the government in power reflecting Taiwanese aborigines' history.

\section{FIELD AND PROCEDURE}

\section{A. The Field}

Smangus is a community of a tribe of Tayal people, in the depths of a mountain area (Elevation: 1,200 m) southeast of Taipei. It has a population of 115 and 33 households (in 2010, the time of a field work) and residents are almost the Tayal except for school teachers of Chinese origin and a few foreign brides. Smangus was particularly behind in development in Taiwan until the beginning of 1990s due to its remote location, however, it is now famous for its community management system based on common-ownership also for ethnic tourism, and it is also well-known for a successful application of CD by Taiwanese aborigines.

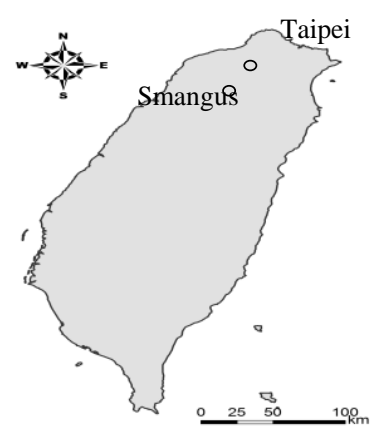

Fig. 1. The location of Smangus.

\section{B. Procedure}

It is empirically known that strong leadership lead participatory CD in Taiwan and also Taiwanese aborigines are. Smangus' case is no exception, and this paper divides residents into community leaders (hereinafter referred as leaders) and general residents (hereinafter referred as residents), and focus on leaders to investigate their agent/agency to the inside of the community because they started CD activities. Leaders are several residents which consists of the head of the community (Marhuw: described later), and reliable assistants.

The following procedure is divided into two parts. One part is to demonstrate leaders' agency and used a qualitative and a quantitative approach. Initially, semi-structured interviews with some leaders were conducted to understand three topics, which were the original tradition in past times, the process of $\mathrm{CD}$ including reviving traditions and the current community management system. Next, the new system was compared with the original tradition to clarify the transformation of revived traditions' functions in the system and considered evidence of resistance and communication. After that, a complementary questionnaire with all residents was conducted to understand reasons for agreement with the new system and considered how much leaders and residents formed common feelings when starting the new system.

The other part is to understand the leaders' agency in the current community conditions using a qualitative approach. Firstly, semi-structured interviews with residents with a brief discussion were conducted to understand the way of life before the new system and their awareness of participation to CD. Secondly, the author conducted participant observation to know residents' current participation to CD. Finally, this paper considered the limitation of leaders' agency

Interviewees were Mr. Y of the executive secretary of the council, Mr. I of the head of CDA and Mr. L of the head of education division. They are in their 30 s and the former two interviewees engaged in $\mathrm{CD}$ from the start. The last interviewee joined leaders after graduating from a graduate school. (Organizations of Smangus are described later).60 questionnaires were distributed to all households, of which 41 were directly returned and usable for analysis. Participant observation was conducted throughout the field work to understand actual $\mathrm{CD}$ activities. 


\section{RESULT}

\section{A. The Past and the Present Way of Life}

Smangus derived from their ancestor's name of Makus who settled this area. They had an ancestral territory divided by the natural boundary around the community by the mountainous area. It formed their identity to inherit the traditional territory obeying Gaga (the common law). The community has a hierarchical management system as shown in Fig. 2. At the top was Utux (the ancestor spirit of the Tayal's belief). Gaga is the common law given by Utux and it strictly ruled the whole community. Next is a Marhuw who actually governed the community and was chosen as the most respectable person.

The most important concept of Gaga was sharing. They did not have a concept of private property and the ancestral territory was the community's common and a prime example of sharing was Qutux-nigan (communal-eating groups) organized more widely than a family unit. Residents exchanged information and talked about anything that occurred in the community. Qutux-nigan was the place residents not only avoided starvation but it also strengthened a sense of solidarity. Even the appointment of Marhuw was not hereditary because Gaga guaranteed equal opportunity. Mrhuw led the community with Nigan (working groups) organized according to purposes of works, such as farm work and the performance of rites.

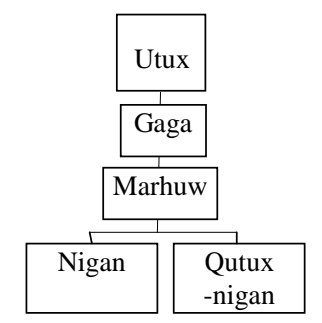

Fig. 2. The original system.

Nowadays, all Tayal residents in Smangus are Christian and their daily life has changed to Chinese-style. The decline of Smangus was serious because the population flow to cities continued since 1980s and traditional customs were forgotten just the same as in other communities of Taiwanese aborigines before starting $\mathrm{CD}$.

\section{B. The Process of $C D$}

Smangus started CD in 1991 to deal with the conditions mentioned in the preceding section. They introduced ethnic tourism focused on a legendary tree of the Tayal which leaders found in the traditional territory after an advanced example in another community. Their business grew taking advantage of the eco-tourism boom, however, it brought two new problems. One was deteriorating human relationship among all residents caused by the economic divide. The other is offers to purchase lands in the community by outsiders to enter the business promoted there.

Leaders were most afraid the latter problem because land sales meant completely losing the Tayal's pride in Smangus, because almost of the traditional territory was already nationalized except for their living area registered as private lands under the Real Property Registration Act by Taiwan's government. They thought that the priority was restoring all residents' relationship with their community in order to protect against land sales. Leaders remembered Qutux-nigan first of all and revived the custom for the needy at leaders' own expense in 1993, and they sought a measure to solve issues and decided on a joint business of tourism.

The joint business started in 2001 after visiting advanced examples and consulting experts. Afterward, they made a joint business rule in 2002, and called on residents to join them. However, residents did not agree with leaders' idea because the rule, which was modelled after Comprehensive CD policy (1994), had stricter rules, such as setting of dues and penalties. Moreover, some residents still wanted to sell

their lands because they could not solve their financial problem any other way. Thus, leaders realized that the rule which copied outsiders' did not suit to the community's conditions and thought of re-establishing common ownership of land in accordance with the Tayal's original rule.

Repeating trial and error, they revived some traditions (in left of Fig. 3) to improve residents' awareness of Tayal identity, and also kept on discussing the idea of common ownership with residents. Finally, 31 of 33 households agreed with the plan of common ownership of tangible and intangible property in the end of 2003. Leaders revived Tayal's contract ceremony and 31 households made a contract for common-ownership in the rite at the beginning of 2004, and the new system called Tnunan-Smangus (TS: Smangus of sharing) started. The contract stipulated that lease and sale of the land in the community is prohibited and leaders finally achieved their goal 10 years after the emergence of problems. Afterward, leaders revived agricultural rites in 2005 and held a harvest festival combined with Thanksgiving Day in Smangus church in 2009.

\section{The Outline of TS}

TS is hierarchically organized according to the original system as follows. The first is three organizations of the community council (hereinafter referred as the council), the community development association (CDA) and Smangus church (SC). The second is Mrhuw and the executive secretary, and the third is 9 working divisions. Any residents above 18-year-old who have family registers and live in Smangus can join TS without dues. Mr. L said that 90 of 115 had joined TS at the time of a field work.

The council is the highest body, which is responsible for making decisions, and all members not only have to attend a monthly meeting, but also can state any opinion about daily life. The council not only guarantees all expenses of the life, but also assigns members to working divisions and pays them allowance, which is equivalent to the minimum wage in Taiwan, although members cannot have private property. CDA and SC are liaison organizations between administrative bodies and the upper echelons of church. As the above system suggests. 


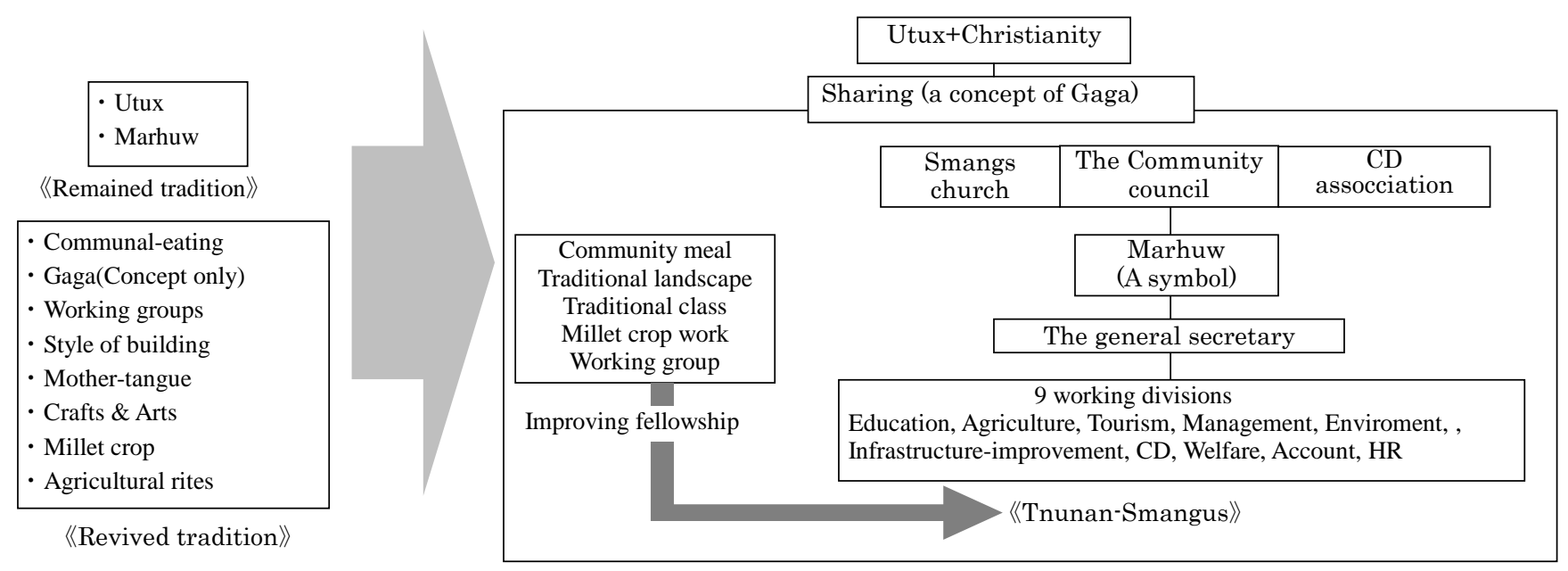

Fig. 3. The transformation of traditions to the system of TS (Made by the author based on interviews).

\section{The Reflection of Traditions to TS}

Fig. 3 illustrates main transformations of the original traditions. The status of Mrhuw became a symbolic one and its functions were transferred to residents, with the function of making decisions, given to the council; working management, to the executive secretary; planning activities to the CDA; and holding rites to the SC. Working groups changed to 9 working divisions. Communal-eating was taken into the daily life as free community-meals.

The significance is the reflection of the sharing to the whole of life. In other words, all the activities in Smangus, such as the community management by cooperation of several organizations, community meal and group working, are embodiments of the principal of sharing.

\section{E. Residents' Reaction to Participation in TS}

Residents' reaction to participation in TS is considered in this section because almost all of the process to establish TS was advanced by leaders only. It is a question whether residents share sense of concern about the community's condition and independently agree with TS.

Table I shows the reasons for agreement to TS. There are three categories in the question which are self-determination, Lemming mentality and Agreed by compulsion. Most of respondents selected answers under the category of self-determination and the majority selected "understanding" and "the desire to contribute". Residents said that the deteriorating human relationship was very serious and quarrels were frequent even among family members (Table II: upper). Regarding a source of information (Table III), it is not surprising that the majority (15/24) chose "TS orientation meetings", while the answer of "family members" suggested that residents could get information of TS even if they were absent, and 3 respondents who selected "in the community by chance" answered that they talked with leaders more than five time before agreement. Moreover, a resident who did not agree with TS said that he discussed with leaders for many times. As a result, communication between leaders and residents can be said to have been sufficient. This indicates that residents' awareness of participation is sufficiently high when the agreement is achieved through discussion with leaders as mentioned in the previous section.

\begin{tabular}{|c|c|}
\hline \multicolumn{2}{|c|}{ 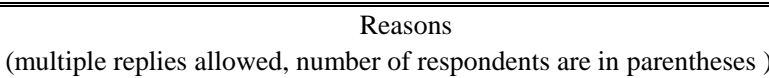 } \\
\hline \multirow{6}{*}{ Self-determination } & Understood what TS is (18) \\
\hline & To contribute to the community (17) \\
\hline & To improve my own life (15) \\
\hline & To improve the community's life (14) \\
\hline & Leaders listened to my opinions (8) \\
\hline & Agreed with leaders' idea (8) \\
\hline \multirow{6}{*}{ Lemming mentality } & Leaders are good men (5) \\
\hline & Leaders are the authority (5) \\
\hline & Leaders have specialized knowledge (2) \\
\hline & Most residents agreed (4) \\
\hline & My family or friends agreed (3) \\
\hline & My family or friends asked me (1) \\
\hline \multirow{2}{*}{ Agreed by compulsion } & Leaders forced me to agree $(0)$ \\
\hline & No choice but to agree (2) \\
\hline
\end{tabular}

TABLE II: A RESULT OF INTERVIEWS WITH RESIDENTS

\begin{tabular}{|c|c|}
\hline $\begin{array}{l}\text { How were the } \\
\text { community's } \\
\text { conditions } \\
\text { before TS? }\end{array}$ & $\begin{array}{l}\text { - Human relationship was very bad. } \\
\text { - Quarrels frequently occurred even among a family due } \\
\text { to economic divide. } \\
\text { - I discussed with leaders many times but I could not } \\
\text { understand TS's merit for me and I disagreed after all. }\end{array}$ \\
\hline $\begin{array}{l}\text { What do you } \\
\text { think about TS? }\end{array}$ & $\begin{array}{l}\text { - I never starve of death as long as I belong to TS. } \\
\text { - I do not need to do anything except for working in the } \\
\text { community because leaders deal with everything. } \\
\text { - I am not going to high school because TS give me money }\end{array}$ \\
\hline $\begin{array}{l}\text { What do you } \\
\text { think about } \\
\text { Gaga? }\end{array}$ & $\begin{array}{l}\text { - The rule of the life } \\
\cdot \text { I do not like Gaga because it is very strict but I must obe) } \\
\text { it. } \\
\cdot \text { I fear Gaga because I cannot enter Paradise if I do not } \\
\text { obey it. }\end{array}$ \\
\hline \multicolumn{2}{|r|}{ TABLE III: HOW DID YOU KNOW ABOUT TS? $(N=24)$} \\
\hline & $\begin{array}{l}1 \text { In TS orientation meetings (15) } \\
2 \text { From family members (6) } \\
3 \text { In the community by chance (3) }\end{array}$ \\
\hline
\end{tabular}

Residents have recovered a sense of solidarity now and ethnic tourism has currently made enough profit to maintain the system. As a result, residents' support for participation seemed to decline, because they said that they did not need to worry about anything because they can rely on leaders. Results of participant observation showed that participants of 
a monthly meeting were only about a half of TS members in total and that young people sometimes escape working.

\section{DISCUSSION}

\section{A. The Agency of Leaders}

Leaders' agency to inside of the community found in the results described in detail in the above sections and can be summarized as follows.

Firstly, leaders adhered to their principal of communication over 10 years to reach an agreement of TS. Interviewees told that their efforts of explaining their idea and listening to residents' opinions for many times led them to the establishment of TS. Results of the questionnaire and interviews verified leaders' opinions. On the other hand, leaders continued to promote the sharing doctrine of Gaga in tangible ways. Communal-eating is a prime example, and also, revival of the traditional style of building and working groups imply the purpose of improving residents' sense of solidarity as well as controlling landscape appearance and promoting greater efficiency. Millet crop was the staple food for Taiwanese aborigines in those days and also the reason why they revived millet crop work was. This is not agriculture group's work but the whole TS residents are required to join the work although any one no longer eats it in daily lives.

Some residents criticized reviving traditions because it conflicted with Christianity. Actually 11 of 41 respondents selected "Strongly agree" and "agree" to a question of which

"I think tradition and Christianity have conflicts" in the questionnaire. Interviewees told that Smangus really needed to settle the issue because they could not get approval of TS if conflict remained between religions. This was why they named the system TS. Tnunan is a coinage based on a Tayal word. It means communication and union not only for residents but only for Utux and Christianity. It was not probably very difficult as before TS because leaders already restored residents' common feelings. They supported the legitimacy of Utux by holding rites in a community church with SC's effort to arrange the rites.

These discussions indicate that leaders' agency worked stronger to residents than to other stakeholders although they succeeded in avoiding conflict with the upper echelons of church by SC's support as an liaison organization, and administrative bodies appreciate a CDA, so long as it works in accordance with a provision of CD policy, and applies various policies to implement the community's plan, such as infrastructure improvement (for which originally administrative bodies had the responsibility).

Some key factors in Smangus success are found in the CD practice in Smangus, for example, leaders' patient efforts over 10 years and transforming traditions not for tourism but for the quality of the community's life. The further significance among these was the coherent direction leaders kept. When started CD, leaders adopted Gaga's doctrines of sharing as the key to restoring Smangus' community spirit. Also, the purpose of TS which leaders specially emphasized to residents was restoring Gaga of the sharing. Leaders efficiently constructed TS system based on this coherent direction. As a result, Gaga was changed from the strict rule to the basis of residents' relationship.

Thus, leaders intervened in the community's situation and changed it in the process to establish TS. TS is a result of transforming the obstacles: residents' doubt to TS, the friction between administration bodies around aborigines' issues and the inconsistency between Utux and Christianity.

\section{B. The Continuity of TS}

Contrary to leaders' unchanged efforts, residents' awareness of participation has declined after TS finally worked. Regarding escaping, leaders tried to preach young people about previous Gaga's spirits, however, it will be difficult for leaders to control them by the traditional doctrine because their life already changed.

This may be an expected phenomenon, however, an awareness gap between leaders and residents implies the vulnerability of the continuity of TS. It will be worth ensuring that leaders share experiences of reviewing the community's life and transforming the tradition to develop residents' sense of ownership of the community management and to generate intervention between them in the future.

\section{CONCLUSION}

The paper pointed out actors' agency in Smangus case. Discussions in the previous sections also imply that features of intervention by resistance and communication made their actions strategic and improve their capacity to engage in $\mathrm{CD}$ practice. However, the continuity of $\mathrm{CD}$ from the agent/agency perspective was not enough. It is required to focus on residents' agency to discuss the result of TS practice as a future work. This paper will to continue observing their practice.

\section{ACKNOWLEDGMENT}

The author thanks Sumangus people for that they kindly accepted my visit and cooperated in interviews and questionnaire.

\section{REFERENCES}

[1] M. H. Wang, "Independence by Eco-tourism," in Overcoming the Poverty and Tourism, 1 st ed, N. Eguchi, M. Fujimaki Ed., Japan: Akahi syoten, 2010, part 2, pp. 147-183.

[2] T. Sasaki, S. Hoshino, Y. Kuki, and S. Hashimoto, "The Issues of Community Development by Indigenous People in Taiwan - A case study in Sansen-li, Tai-dong city-dong," The Association of Rural Planning, Journal of Rural Planning, vol. 30, no. special-issue, pp. 369-374, November 2011.

[3] A. Giddens, Modernity and Self-Identity: Self and Society in the Late Modern Age, 1st ed. Cambridge, U.K.: Polity Press, 1991, ch. 7, p. 215.

[4] A. Giddens, The Nation States and Violence, Cambridge, U.K.: Polity Press, 1985, ch. 1, pp. 7.

[5] M. Tanaka, "From subject to agent of community," Ethnography by Practices in the Daily Life, 1st ed., S. Tanabe, M. Matsuda Ed., Japan: Sekaishisosha Co., Ltd, 2002, ch. 13, pp. 337-360.

[6] M. Eto. (February 2004). Gender of Politics, Citizenship and Agency. Hosei University Repository, Hougaku-shirin, [Online]. no. 101, pp. 5-44. Available: http://hdl.handle.net/10114/2244

[7] Y. Miyanishi, "Machidukuri is development of the community capacity, residents' power and the revitalization of the urban areas," The City Planning Institute of Japan, Reports of the City Planning Institute of Japan, vol. 143, pp. 25-33, August 1986. 
[8] J. Hirota, "Thinking community development again," The Association of Rural Planning, Journal of Rural Planning, vol. 28, no. 4, pp. 401-404, March 2010.

[9] A. Yoshimura and J. Hirota, "Factors to form residents' independence in a process of community development," The Association of Rural Planning, Journal of Rural Planning, vol. 25, no. Special Issue, pp. 305-310, November 2007.

[10] B. K. Liang and C. Y. Zhang, "Cultural economy and social capital of aboriginal tribe tourism-a case study of Saviki Community," Journal of Geography Science, Taiwan University, vol. 39, pp. 31-51, 2005.

[11] R. Takahashi, "Agriculture financing as a safety net in agriculture development - a case study of farmer union in Sénégal River Area under rice-farming promote policy," Japan Association for African Studies, Journal of African Studies, vol. 2009, no. 74, pp. 1-17, 2009.

[12] X. J. Tsai, "A study of the joint business in Smangus," Providence University, Master thesis, May 2005.

[13] L. Icheh, "Who can discuss these knowledge? Forming Residents' Independence and Practice of Local Knowledge," Providence University, Master thesis, May 2008.

[14] Y. Napay, "Tourism and multicultural education in Smangus, a practice of Tayals to make the community to a classroom," The Japan
Association for Taiwan Studies, Journal of Japan-Taiwan Studies, vol. 11, pp. 177-198, May 2009.

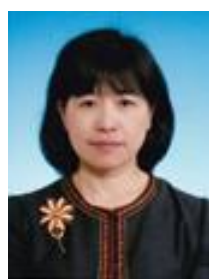

Takako Sasaki was born in Gifu, Japan, on January 11, 1962. She obtained BA in Geography in 1984 from Ritsumeikan University, Japan, and MA degree in Rural Planning in 2012 from Kyoto University, Japan. She is a $\mathrm{PhD}$ student at the graduate school of Agriculture, Kyoto University. Her research interest include residents' independence in community development, community-based disaster risk reduction and disaster risk reduction edycation.

She engaged in volunteer with an environmental NPO in Taiwan and Japan as a volunteer coordinator from 2004 to 2010, then entered in a graduate school to study participatory community development activity in Taiwan. She received a research award and published articles on Rural planning field. 